\title{
Uso da ampicilina sódica e cloranfenicol no controle de contaminantes na micropropagação de bananeira 'Thap maeo' 1
}

\author{
Gustavo Alves Pereira², Aparecida Conceição Boliani ${ }^{3}$, Enes Furlani Junior ${ }^{4}$
}

\section{RESUMO}

A micropropagação vem sendo desenvolvida e aperfeiçoada para elevar a taxa de multiplicação de plantas em curto espaço de tempo e melhorar a qualidade da produção de mudas. Contudo, a contaminação microbiana é um dos maiores problemas desta técnica. Este trabalho teve por objetivo avaliar a eficiência da descontaminação de explantes de bananeira durante o estabelecimento in vitro, com o uso dos antibióticos ampicilina sódica e cloranfenicol adicionados ao meio de cultura. O delineamento experimental utilizado foi o inteiramente casualizado constituído de cinco tratamentos e cinco repetições, sendo cada repetição representada por cinco explantes em diferentes concentrações de ampicilina sódica e cloranfenicol por vinte minutos. Os antibióticos foram adicionados separadamente ao meio de cultura em concentrações de $0,5,10,15$ e $20 \mathrm{mg} \mathrm{L}^{-1}$. Os dados foram submetidos à análise de variância e as médias comparadas pelo teste $\mathrm{F}$ e análise de regressão. Foram avaliadas as porcentagens de contaminação por bactérias, fungos e oxidação dos explantes. Os resultados permitiram concluir que os antibióticos apresentaram controle sobre contaminantes endógenos nos explantes de banana 'Thap maeo'. A concentração de $20 \mathrm{mg} \mathrm{L}^{-1}$ dos antibióticos ampicilina sódica e cloranfenicol proporcionou redução de $70 \%$ na infecção por bactérias e fungos.

Palavras-chave: Musa sp, cultura de tecidos, descontaminantes.

\section{ABSTRACT \\ Use of the antibiotics sodium ampicillin and chloramphenicol to control contamination in micropropagation of 'Thap maeo' banana}

Micropropagation has been developed to enhance the multiplication rate in a short time and improve seedling quality. However, microbial contamination is a major problem in micropropagation. This study aimed to evaluate the efficiency of decontamination of banana explants during in vitro establishment with the addition of the antibiotics sodium ampicillin and chloramphenicol to the culture medium. The experiment was arranged in a completely randomized design, consisting of five treatments and five replicates. Each replicate consisted of five explants in different concentrations of sodium ampicillin and chloramphenicol for twenty minutes. Antibiotics were added separately to the culture medium at concentrations of $0,5,10,15$ and $20 \mathrm{mg} \mathrm{L}^{-1}$. The data were analyzed using ANOVA and the means were compared by $\mathrm{F}$ test and regression analyses. We evaluated the percentage of contamination by bacteria, fungi and oxidation of the explants. The results showed that antibiotics had control over endogenous contaminants in 'Thap maeo' banana explants. The concentration of $20 \mathrm{mg} \mathrm{L}^{-1}$ of each antibiotic reduced in $70 \%$ the incidence of bacteria and fungi.

Key words: Musa sp, tissue culture, decontaminants.

\footnotetext{
Recebido para publicação em 04/03/2013 e aprovado em 31/10/2013.

${ }^{1} 1$ Este trabalho é parte da tese de doutorado do primeiro autor.

2 Engenheiro-Agrônomo, Doutor. Departamento de Fitotecnia, Tecnologia de Alimentos e Sócio Economia, Universidade Estadual Paulista "Júlio de Mesquita Filho", Campus de Ilha Solteira, Avenida Brasil, 56, 15385-000, Ilha Solteira, São Paulo, Brasil. gustavo_apereira@yahoo.com.br (autor para correspondência).

3 Engenheira-Agrônoma, Doutora. Departamento de Fitotecnia, Tecnologia de Alimentos e Sócio Economia, Universidade Estadual Paulista "Júlio de Mesquita Filho", Campus de Ilha Solteira, Avenida Brasil, 56, 15385-000, Ilha Solteira, São Paulo, Brasil. boliani@agr.feis.unesp.br

4 Engenheiro-Agrônomo, Doutor. Departamento de Fitotecnia, Tecnologia de Alimentos e Sócio Economia, Universidade Estadual Paulista "Júlio de Mesquita Filho", Campus de Ilha Solteira, Avenida Brasil, 56, 15385-000, Ilha Solteira, São Paulo, Brasil. enes@agr.feis.unesp.br
} 


\section{INTRODUÇÃO}

O Estado de São Paulo é o maior produtor de banana do País. Em 2013 teve produção de 1.204.878 toneladas, produzidas em uma área de 54.563 hectares, seguido da Bahia com 1.100.540 toneladas (AGRIANUAL, 2014). A propagação da bananeira (Musa sp.) pode ser feita de várias formas: por sementes, ou vegetativamente por meio de mudas tipo chifrão, chifre e chifrinho ou in vitro. Pelo método tradicional (rizomas), mesmo o material sendo de ótima qualidade, o processo é lento e permite a disseminação de doenças e pragas dentre as quais se destacam a sigatoka negra e amarela, mal do panamá e a broca do rizoma (Souza et al., 2006).

Um dos requerimentos básicos para o sucesso da micropropagação consiste, em parte, de medidas de controle e prevenção da contaminação microbiana (Leifert et al., 1994; Silva et al., 2003) devido a esta técnica proporcionar um ambiente favorável para o crescimento de microrganismos como bactérias, leveduras e fungos filamentosos (Dantas et al., 2002).

Os microrganismos contaminantes competem com os explantes pelos nutrientes do meio de cultura, liberando no meio metabólitos tóxicos que podem ocasionar a morte da planta (Pereira et al., 2003).

A contaminação bacteriana é bastante nociva para os cultivos in vitro, principalmente quando ocorre por bactérias latentes ou endógenas, introduzidas sistemicamente com os explantes, impondo consideráveis limitações na fase de iniciação in vitro (Ferreira et al., 2009).

Os desinfestantes superficiais como álcool ou hipoclorito de sódio muitas vezes podem controlar apenas os fungos, mas não garantem níveis aceitáveis de controle para bactérias, o que pode ser constatado por Vianna et al. (2003), os quais utilizaram como descontaminante para os explantes de mamoeiro apenas hipoclorito de sódio em diferentes concentrações, sendo impossível conseguir explantes sem sinais visíveis de contaminação, principalmente por bactérias. Para o controle das bactérias, diversos autores citam a inclusão ao meio de cultura de antibióticos como ampicilina sódica, agrimicina, cloranfenicol, acido nalidíxico (Wilson \& Power (1989), Garcia \& Rafael (1990); Barros \& Pasqual (1991), Leifert et al. (1991), Pereira et al., (2010), Palu et al. (2011). Também se pode adicionar os antibióticos ao meio de cultura por um período limitado, o necessário para a eliminação dos contaminantes (Kneifel \& Leonhardt, 1992, Leifert et al., 1992) ou utilizá-los na forma de imersão antes do isolamento (Tanaka et al., 1983, Scortichini \& Chiariotti, 1988).

Muitos antibióticos apresentam efeito fitotóxico, alterando o crescimento in vitro (Dodds \& Roberts, 1985). Alguns antibióticos podem causar fitotoxicidade, em função da concentração à qual o tecido foi exposto e da tole- rância da espécie tratada (Okkels \& Pedersen, 1988). A concentração de cloranfenicol inibiu em $50 \%$ a regeneração em beterraba e cenoura in vitro. Quando se utilizou estreptomicina, a cenoura apresentou maior tolerância do que a beterraba (Okkels \& Pedersen, 1988).

Os antibióticos são usados para o controle de contaminações bacterianas endógenas, representando sério problema no estabelecimento das culturas. Os explantes, após a redução dos contaminantes superficiais, podem ser transferidos para meio nutritivo contendo antibiótico (Grattapaglia \& Machado, 1998). Esses autores citam que o antibiótico deve ser esterilizado a frio e adicionado ao meio antes da sua solidificação, e também apresentar um amplo espectro de ação. Os antibióticos mais usados em cultura de tecidos vegetais possuem ação bacteriostática e não bactericida. Em laboratórios comerciais de micropropagação de plantas, Leifert et al. (1991) identificaram 293 espécies de bactérias, das quais 13\% pertenciam ao gênero Bacillus. As espécies deste gênero formam endósporos resistentes ao álcool e ao calor, podendo, inclusive, ser disseminadas pelo álcool utilizado na esterilização dos instrumentos e resistir à flambagem e à autoclavagem do meio de cultura, por 20 minutos a $110^{\circ} \mathrm{C}$ (Boxus \& Terzi, 1987, Nannetti, 1994).

Na multiplicação in vitro de bananeira comumente são observados níveis elevados de contaminação por bactérias (Oliveira et al., 2001, Sá \& Braga, 2001). Níveis de contaminação abaixo de $2 \%$, nos subcultivos, são usualmente considerados como o mínimo requerido para garantir sucesso na produção (Leifert \& Woodward, 1998).

Na cultivar de bananeira Caipira, por exemplo, Braga et al. (2001) quantificaram perdas de $75 \%$ dos explantes na fase de estabelecimento. Perdas essas causadas por Pseudomonas maltophila, Bacillus sp., Klebsiella pneumonia e Hafnia alve, que podem inviabilizar a multiplicação em nível comercial porque oneram o processo de multiplicação in vitro. Do ponto de vista prático, a melhor medida a ser tomada consiste no descarte do material contaminado. Entretanto, no caso da necessidade de manutenção do material vegetal contaminado, torna-se imprescindível efetuar o controle curativo dessas bactérias com o uso de antibióticos específicos. Isso, porém, nem sempre resulta em controle completo da contaminação. Assim, torna-se necessário testar antibióticos alternativos, isolados ou em combinação, tanto para utilização em meio de cultura ou imersão dos explantes, bem como na pulverização das plantas matrizes no campo (Pereira et al., 2003).

O objetivo do trabalho foi avaliar a eficiência da descontaminação de explantes de bananeira durante o estabelecimento in vitro com o uso de diferentes concentrações dos antibióticos ampicilina sódica e cloranfenicol adicionados ao meio de cultura. 


\section{MATERIAL E MÉTODOS}

O presente trabalho foi conduzido no Laboratório de Micropropagação do Departamento de Fitotecnia, Tecnologia de Alimentos e Sócio-Economia da Faculdade de Engenharia da Universidade Estadual Paulista (UNESP), Campus de Ilha Solteira-SP, no período de 10 de maio a 10 de junho de 2011.

No experimento foram utilizadas mudas de bananeira do tipo chifrinho da variedade 'Thap maeo', procedentes da Fazenda de Ensino, Pesquisa e Extensão da Faculdade de Engenharia da UNESP, localizada em Selvíria-MS.

O experimento foi constituído da adição de concentrações do antibiótico ampicilina sódica e cloranfenicol ao meio de cultura. Os tratamentos foram os seguintes: T1 Testemunha - $0 \mathrm{mg} \mathrm{L}^{-1}$ de ampicilina sódica, T2 - $5 \mathrm{mg} \mathrm{L}$ ${ }^{1}$ de ampicilina sódica, T3 - $10 \mathrm{mg} \mathrm{L}^{-1}$ de ampicilina sódica, T4 - $15 \mathrm{mg} \mathrm{L}^{-1}$ de ampicilina sódica, T5 - $20 \mathrm{mg} \mathrm{L}^{-1} \mathrm{de}$ ampicilina sódica, T6 - $5 \mathrm{mg} \mathrm{L}^{-1}$ de cloranfenicol, T7 - 10 $\mathrm{mg} \mathrm{L}^{-1}$ de cloranfenicol, $\mathrm{T} 8$ - $15 \mathrm{mg} \mathrm{L}^{-1}$ de cloranfenicol e T09 - $20 \mathrm{mg} \mathrm{L}^{-1}$ de cloranfenicol.

O meio de cultura utilizado foi o MS (Murashige \& Skoog, 1962), suplementado com $30 \mathrm{~g} \mathrm{~L}^{-1}$ de sacarose e 2,3 $\mathrm{g} \mathrm{L}^{-1}$ de phytagel, com $\mathrm{pH}$ ajustado para 5,8 antes da autoclavagem a $120^{\circ} \mathrm{C}$ com $1 \mathrm{kgf} \mathrm{cm}^{-2}$ durante 20 minutos, sendo vertido em potes de vidro com capacidade de 200 $\mathrm{mL}$, cada recipiente recebendo $20 \mathrm{~mL}$ de meio. As concentrações dos antibióticos correspondentes aos tratamentos foram adicionadas ao meio de cultura, ainda morno e em estado líquido, após sua esterilização, dentro da câmara de fluxo laminar, para não prejudicar a ação dos antibióticos.

Após a obtenção dos rizomas, os mesmos foram lavados em água corrente, sendo retirados o excesso de solo e raiz. Em seguida, as bainhas foram seccionadas com uma faca esterilizada, permitindo assim a redução de seu tamanho para $5 \mathrm{~cm}$. Não foi utilizado hipoclorito de sódio na desinfestação para que o mesmo não pudesse interferir nos resultados. A extração dos meristemas foi realizada em condições assépticas em câmaras de fluxo laminar, onde foram inoculados ao meio de cultura com os respectivos tratamentos. A fase de estabelecimento foi realizada em sala de crescimento com temperatura de $25 \pm 2{ }^{\circ} \mathrm{C}$ e fotoperíodo de 16 horas e intensidade luminosa de 30 ìmol $\mathrm{m}^{-2} \mathrm{~s}^{-1}$. Os explantes foram avaliados trinta dias após a data de inoculação, período que compreende a fase de estabelecimento da cultura. Foram avaliadas porcentagens de contaminação por bactérias e fungos e porcentagem de oxidação dos explantes. O delineamento experimental utilizado foi o delineamento inteiramente casualizado com cinco tratamentos, cinco repetições, sendo cada repetição representada por cinco tubos, contendo um explante cada. Os dados foram submetidos à análise de variância utilizando-se o programa SISVAR (Ferreira, 2008), e análi- se de regressão para as concentrações de ampicilina e cloranfenicol.

\section{RESULTADOS E DISCUSSÃO}

De acordo com a análise de variância, pode-se observar que houve diferença significativa entre as concentrações dos antibióticos ampicilina e cloranfenicol para as variáveis porcentagens de contaminação bacteriana, fúngica e explantes oxidados. $(\mathrm{P}<0,05)$. A análise de regressão indicou equações de segundo grau, como melhor ajuste para todas as variáveis.

Os resultados obtidos utilizando o antibiótico ampicilina sódica mostraram que houve redução media de $75 \%$ da contaminação bacteriana. Quando se utilizou o cloranfenicol verificou-se redução de $88 \%$ (Figuras 1 e 2), essa redução foi possível devido à eficiência dos antibióticos utilizados.

Resultados semelhantes foram obtidos por Carneiro et al. (2000) que utilizando hipoclorito de sódio, benomyl, rifampicina e cefotaxima para a descontaminação de explantes de bananeira Maçã, obtiveram êxito adicionando $300 \mathrm{mg} \mathrm{L}^{-1}$ de cefotaxima ao meio de cultura, verificando controle de 73,33\% para bactérias, confirmando que o uso de antibióticos em alguns casos é necessário, concordando com este trabalho.

Os dados obtidos neste trabalho concordam com Lima \& Moraes (2006) que utilizaram explantes em meio nutritivo contendo $100 \mathrm{mg} \mathrm{L}^{-1}$ de rifampicina e constataram sensível redução na multiplicação de bananeira Caipira, não sendo observadas anormalidades nos explantes ou nas plantas.

De acordo com Pereira et al. (2010) que avaliaram diferentes concentrações do bactericida agrimicina na desinfestação de explantes para micropropagação de bananeira IAC 2001, a maior eficiência dentre os tratamentos testados foi o de imersão dos explantes em $4 \mathrm{~g} \mathrm{~L}^{-1}$ do bactericida agrimicina por 20 minutos e as doses testadas não foram fitotóxicas aos explantes.

No presente trabalho, os tratamentos com 5, 10, 15 e $20 \mathrm{mg} \mathrm{L}^{-1}$ de cloranfenicol apresentaram porcentagens respectivas de 80, 64, 44 e $8 \%$ de explantes contaminados por bactérias, concordando com os dados de Héctor et al. (2005) que utilizando $2,5 \mathrm{mg} \mathrm{L}^{-1}$ de cloranfenicol observaram que o uso de cloranfenicol no meio de cultura foi necessário para o controle de bactérias e fungos em menta japonesa. Os mesmos obtiveram $60 \%$ de explantes sadios e com baixa fitotoxidade $(15,4 \%)$.

As informações obtidas no presente trabalho corroboram com Biasi (1995) que em cultivo in vitro de gemas de abacateiro usando o antibiótico cloranfenicol na concentração de $50 \mathrm{mg} \mathrm{L}^{-1}$ obteve redução de contaminação, porém não verificou diferença significativa, e conseguiu $77,4 \%$ de gemas brotadas. 
Em relação à contaminação fúngica, os resultados obtidos mostraram que quando a concentração foi de $20 \mathrm{mg} \mathrm{L}^{-1}$ ocorreu o melhor controle, apresentando redução de $96 \%$ e $78 \%$ quando se utilizou respectivamente os antibióticos ampicilina sódica e cloranfenicol (Figuras 3 e 4 ).
Há poucos relatos de trabalhos que confirmem o uso de antibióticos para a redução da contaminação fúngica, estudos mais aprofundados devem ser realizados com a cultura da bananeira.

A redução da contaminação pode ter ocorrido durante o processo de micropropagação devido à lavagem previa

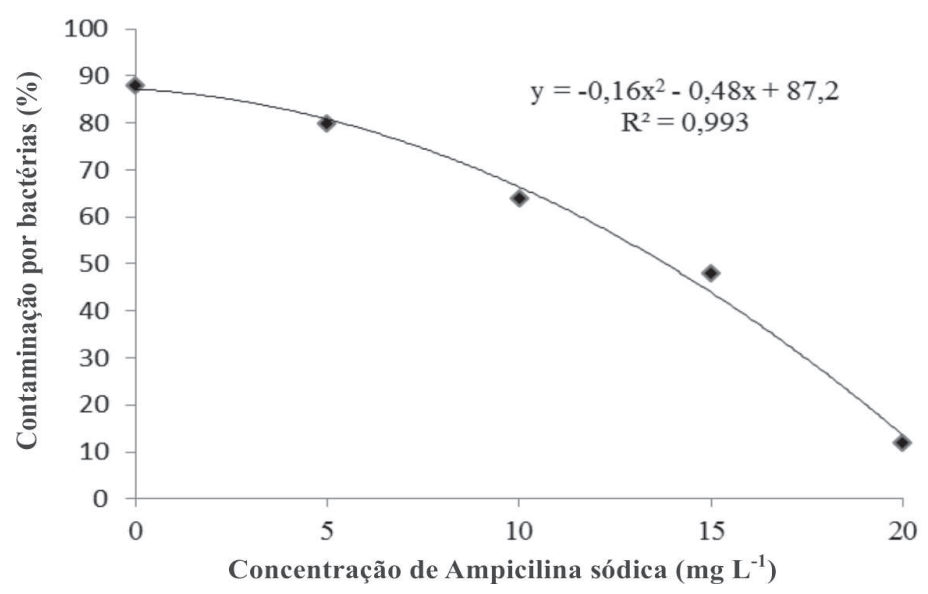

Figura 1. Porcentagem de contaminação bacteriana em explantes de bananeira 'Thap maeo' submetidas a concentrações de ampicilina sódica.

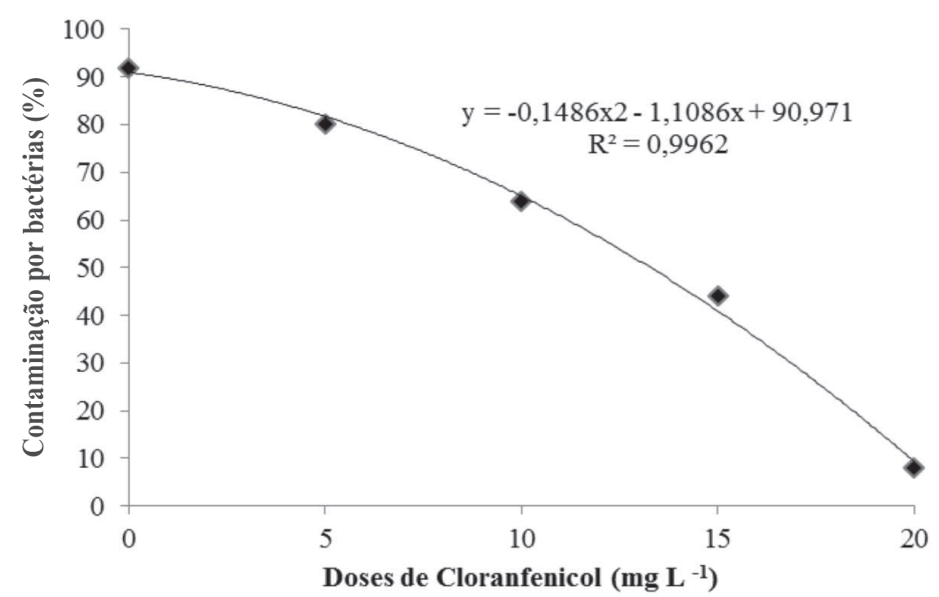

Figura 2. Porcentagem de contaminação bacteriana em explantes de bananeira ‘Thap maeo'submetidas a concentrações de cloranfenicol.

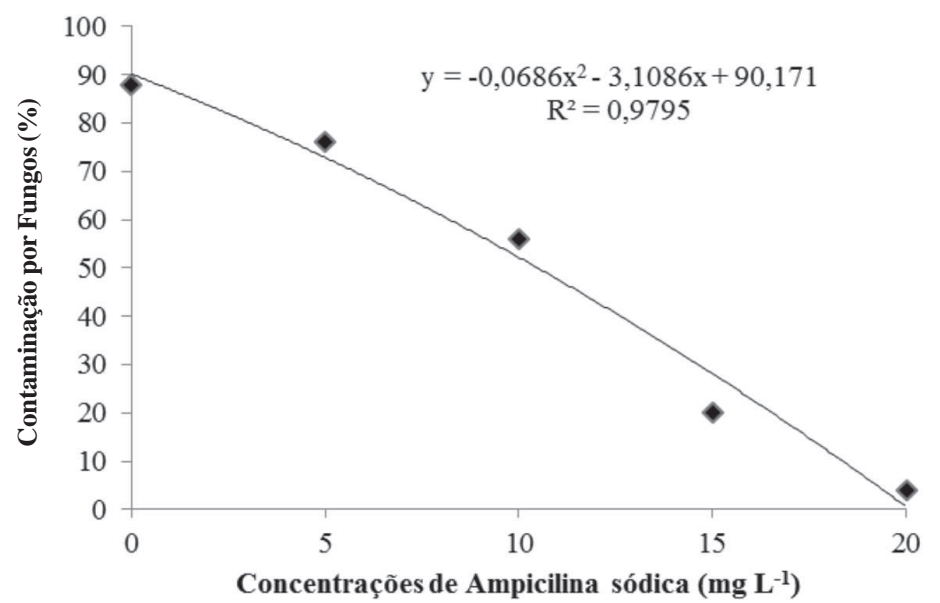

Figura 3. Porcentagem de contaminação por fungos em explantes de bananeira “Thap maeo" submetidas a concentrações de ampicilina sódica.

Rev. Ceres, Viçosa, v. 61, n.3, p. 299-305, mai/jun, 2014 
das mudas em água corrente, redução do tamanho dos explantes e o estabelecimento dos explantes em meio de cultura com os antibióticos realizada em ambiente asséptico.

Em relação a porcentagem de oxidação, nas concentrações de 15 e $20 \mathrm{mg} \mathrm{L}^{-1}$ de ampicilina sódica e cloranfenicol, observou-se aumento, atingindo-se taxas de 52 e $64 \%$ respectivamente, porém sem ocasionar a morte dos explantes
(Figuras 5 e 6). Esse aumento pode estar ligado ao principio ativo dos antibióticos, mas que requer mais estudos.

Por outro lado as informações obtidas neste trabalho discordam de Palu et al. (2011) que em micropropagação de figueira utilizaram $30 \mathrm{mg} \mathrm{L}^{-1}$ de cloranfenicol e $250 \mathrm{mg}$ $\mathrm{L}^{-1}$ de ácido nalidixico e obtiveram $30,82 \%$ e $0 \%$ de explantes oxidados respectivamente.

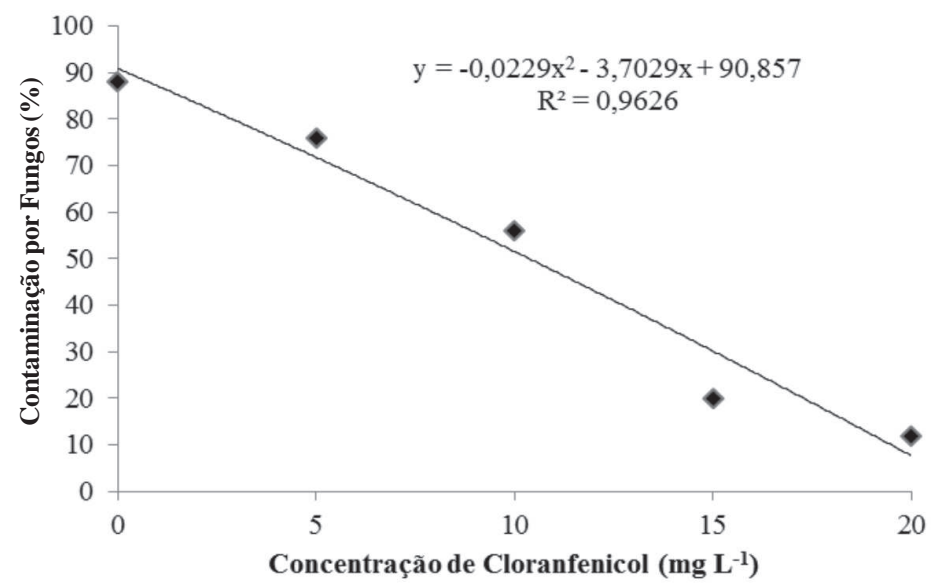

Figura 4. Porcentagem de contaminação por fungos em explantes de bananeira 'Thap maeo" submetidas a concentrações de cloranfenicol.

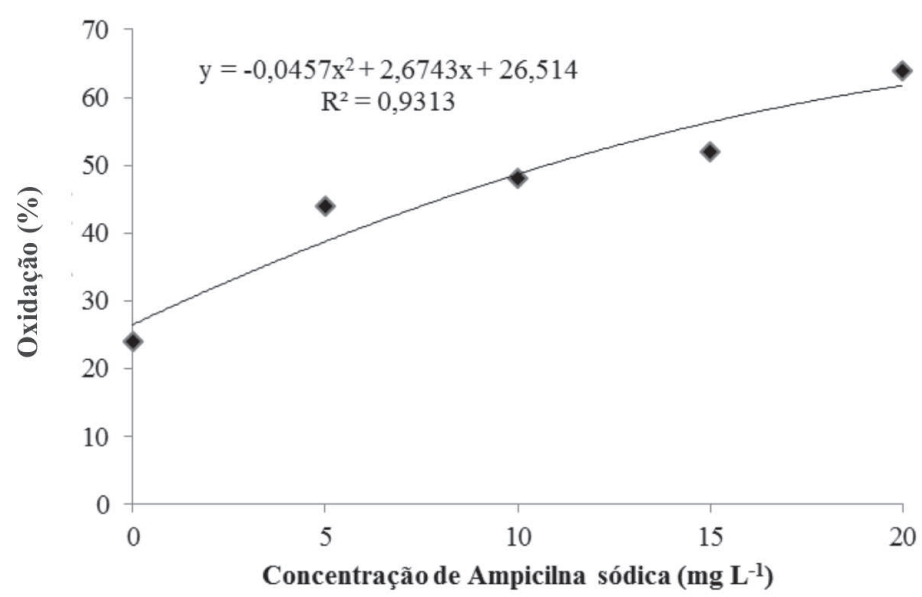

Figura 5. Porcentagem de oxidação em explantes de bananeira 'Thap maeo” submetidas a concentrações de ampicilina sódica.

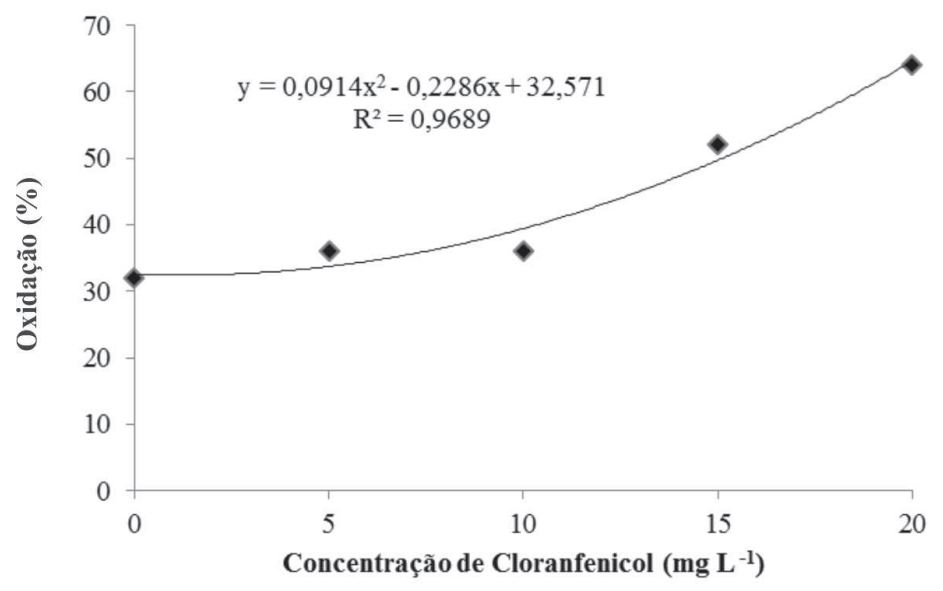

Figura 6. Porcentagem de oxidação em explantes de bananeira "Thap maeo” submetidas a concentrações de cloranfenicol. 
Biasi (1995) utilizando ácido nalidíxico, cloranfenicol e estreptomicina, em abacateiro observaram que todas as concentrações desses antibióticos adicionadas ao meio de cultura $\left(0,12,5,25,50,100\right.$ e $\left.200 \mathrm{mg} \mathrm{L}^{-1}\right)$ restringiram o comprimento das brotações, concluindo que os três foram tóxicos para o abacateiro, sendo recomendados apenas em casos de extrema necessidade, dependendo da suscetibilidade do microorganismo contaminante e da concentração necessária para seu controle.

\section{CONCLUSÕES}

Os antibióticos ampicilina sódica e cloranfenicol apresentam controle sobre contaminantes endógenos nos explantes de banana 'Thap maeo'. A concentração de 20 $m g \mathrm{~L}^{-1}$ dos antibióticos reduz a contaminação por bactérias e fungos, apresentando também taxa de oxidação não nociva aos explantes.

\section{REFERÊNCIAS}

Agrianual (2014) Anuário da agricultura brasileira. São Paulo: Informa economics/FNP 167p.

Barros I \& Pasqual M (1991) Contaminação fúngica, bacteriana e oxidação in vitro de explantes de Coffea arabica L. cv. Catuaí. Ciência e Prática, 15:145-153.

Biasi, LA (1995) Fitotoxicidade de três antibióticos na cultura in vitro de abacateiro. Bragantia, 54:251-256.

Boxus PH \& Terzi JM (1987) Big losses due to bacterial contamination can be avoided in mass propagation scheme. Acta Horticulturae, 212:91-103.

Braga MF, Sá MEL \& Mustafá, PC (2001) Avaliação de um protocolo para multiplicação in vitro da bananeira (Musa sp.) cv. Caipira (AAA). Revista Brasileira de Fruticultura, 23:215-219.

Carneiro MF, Silva GD, Ximenes PA, Carneiro IF \& Borges JD (2000) Avaliação de produtos na descontaminação de explantes de banana (Musa AAB cv. Maçã). Pesquisa Agropecuária Tropical, 30:29-35.

Dantas S, Oliveira S \& Câmara T (2002) Contaminação microbiana no cultivo in vitro de plantas. Revisão Anual de Patologia de Plantas, 10:391-407.

Dodds JH \& Roberts LW (1985) Experiments in plant tissue culture. Cambridge University Press, 232p.

Ferreira, DF (2008) SISVAR: um programa para análises e ensino de estatística. Revista Symposium, 6:36-41.

Ferreira MGR, Santos MRA \& Bragado ACR (2009) Propagação in vitro de cupuaçuzeiro: desinfestação de explantes florais. Saber Científico, 2:37-44.

Garcia EG \& Rafael M (1990) Control de la oxidación y contaminación en microesquejes de café (Coffea arabica 'Catimor') cultivados in vitro. Agronomia Tropical, 40:281290.

Grattapaglia D \& Machado MA (1998) Micropropagação. In: Torres AC, Caldas LS, Buso JA. Cultura de tecidos e transformação genética de plantas. Brasília, EMBRAPA/SPI. p.183-260.

Héctor E, Barrón ML, Godoy L, Díaz B \& Torres MMHA (2005) Un método para la desinfección y el establecimiento in vitro de la menta japonesa (Mentha arvensis L.). Cultivos Tropicales, 26:69-71.
Kneifel W \& Leonhardt W (1992) Testing of different antibiotics against Gram-positive and Gram-negative bacteria isolated from plant tissue culture. Plant cell, tissue and organ culture, 29:139144.

Leifert C, Morris CE \& Waites WM (1994) Ecology of microbial saprophytes and pathogens in tissue culture and field grown plants; reasons for contamination problems in vitro. Critical Reviews in Plant Sciences, 13:139-183.

Leifert C, Camotta H, Wright SM, Waites B, Cheyne VA \& Waites WM (1991) Elimination of Lactobacillus plantarum, Corynebacterium spp., Staphylococcus saprophyticus and Pseudomonas paucimobilis from micropropagated Hemerocallis, Chisya and Delphinium cultures using antibiotics. Journal of Applied Bacteriology, 71:307-330.

Leifert C, Camotta H \& Waites WM (1992) Effect of combinations of antibiotics on micropropagated clematis, delphinium, hosta, iris and photinia Plant Cell Tissue and Organ Culture, 29:153-160.

Leifert C \& Woodward S (1998) Laboratory contamination management: the requeriment for microbiological quality assurance. Plant Cell Tissue and Organ Culture, 52:83-88.

Lima JD \& Moraes WS (2006) Controle de bactérias contaminantes em explantes de bananeira (Musa AAA cv. Caipira). Pesquisa Agropecuária Tropical, 36:181-186.

Murashige, T \& Skoog, FA (1962). A revised medium for rapid growth and bioassays with tobacco tissue cultures. Physiologia Plantarum, 15: 473-497.

Nannetti DC (1994) Utilização da cultura de tecidos vegetais na micropropagação e manutenção de Heliconia sp. Dissertação de Mestrado. Escola Superior de Agricultura de Lavras, Lavras. $106 \mathrm{p}$.

Okkels FT \& Pedersen MG (1988) The toxicity to plant tissue and to Agrobacterium tumefaciens of some antibiotics. Acta Horticulturae, 225:199-207.

Oliveira RP, Silveira DG \& Silva, S. O (2001) Concentração de BAP e a eficiência de micropropagação de bananeira tetraplóide (grupo AAAB). Scientia Agrícola, 58:73-78.

Palu EG, Correa LS, Suzuki NA \& Boliani AC (2011) Uso de antibióticos para o controle de bactérias endógenas visando à micropropagação da figueira. Revista Brasileira de Fruticultura, $33: 587-592$.

Pereira GA, Bobroff RL, Lenza JB \& Correa LS (2010) Diferentes Concentrações de agrimicina no controle de contaminações de explantes de bananeira na micropropagação. Cultura Agronômica, 19:71-76.

Pereira GA, Ribeiro BV, Marcílio HC \& Santaella MB (2009) Desinfestação e estabelecimento in vitro de explantes de bananeira 'IAC 2001' em diferentes concentrações de hipoclorito de sódio. Tecnologia e Ciência Agropecuária, 3:43-46.

Pereira JES, Mattos MLT \& Fortes GRL (2003) Identificação e controle com antibióticos de bactérias endofíticas contaminantes em explantes de batata micropropagados. Pesquisa Agropecuária Brasileira, 38:827-834.

Sá MEL \& Braga MF (2002) Avaliação de protocolo para obtenção de mudas micropropagadas de bananeira cv. prata-anã (subgrupo AAB). Revista Brasileira de Fruticultura, 24:236239.

Scortichini, M \& Chiariotti A (1988) In vitro culture of Prunus persica var. Laevis Gray (nectarine): detection of bacterial contaminants and possibility of decontamination by means of antibiotics. Acta Horticulturae, 225:109-118. 
Silva JTS, Nhut DT, Tanaka M, Fukai S (2003) The effect of antibiotics on the in vitro growth response of chrysanthemum and tabacco stem transverse thin cell layers (tTCLs). Scientia Horticulture, 97:397-410.

Souza AS, Ledo CAS, Silveira DG, Souza FVD, Faria GA, Neto HPS, Santos Serejo JS, Silva KM, Costa MAPC, Soares TL, Junghans TG \& Almeida WB (2006) Introdução à Micropropagação de Plantas. Cruz das Almas, Embrapa Mandioca e Fruticultura. 151p.
Tanaka M, Kumura M \& Goi M (1983) Surface-sterilization for in vitro culture of phalaenopsis flowerstalk cutting using antimicrobials. Acta Horticulturae, 131:321-328.

Vianna GR, Couto FAA, Oliveira AB, Zambolim L \& Maria J (2003). A rifampicina na descontaminação bacteriana de explantes de mamoeiro provenientes do campo. Bragantia, 56:249-254.

Wilson ZA \& Power JB (1989). Elimination of systemic contamination in explant and protoplast cultures ofrubber (Hevea brasiliensis Muell. Arg.). Plant Cell Reports, 7:622-625. 